\title{
AVALIAÇÃO DO CARÁTER DA PAISAGEM: ABORDAGENS EUROPEIAS
}

\author{
LANDSCAPE CHARACTER ASSESSMENT: EUROPEAN APPROACHES
}

\author{
Virginia Gomes de Luca* \\ Alina Gonçalves Santiago**
}

\section{RESUMO}

O caráter da paisagem resulta da combinação particular dos atributos definidores do padrão de paisagem por meio dos elementos que distinguem uma paisagem da outra, cujo arranjo é modelado pelas ações culturais e naturais de cada local. A abordagem de cunho teórico perpassa por alguns autores e algumas organizações internacionais europeias, principalmente do Reino Unido e da Espanha. O presente estudo tem como objetivo apresentar uma breve proposta para - estudo da paisagem a partir do enfoque da Convenção Europeia da Paisagem (CEP). A CEP, aprovada em 2000 em Florença, compreende a relação entre os aspectos naturais e culturais da paisagem com foco no desenvolvimento sustentável e na relação equilibrada e harmoniosa entre as necessidades sociais, econômicas e ambientais de cada comunidade, e tem como objetivo promover a proteção, a gestão e o ordenamento da paisagem. Sendo assim, é possível proteger a paisagem por meio de ações de conservação e manutenção dos traços significativos ou característicos de uma paisagem, justificadas pelo seu valor patrimonial resultante da configuração natural ou da intervenção humana. Como as paisagens sempre mudaram e continuarão a mudar, seja por processos naturais ou pela ação humana, faz-se necessário o acompanhamento das mudanças no sentido de enriquecer a diversidade e a qualidade de cada uma delas.

Palavras-chave: Caráter da paisagem. Avaliação do caráter da paisagem. Convenção Europeia da Paisagem.

\section{ABSTRACT}

The landscape character results from the particular combination of the defining attributes of the landscape pattern by the elements that distinguish a landscape from another, whose arrangement is shaped by cultural and natural actions of each site. The theoretical approach revisits a few authors and some international European organizations, particularly from the United Kingdom and Spain. The present study aims to introduce a brief proposal for the landscape study from the European Landscape Convention (EPC) viewpoint. The ECP, adopted in 2000 by Florence, understands the relation between natural and cultural aspects of the landscape focusing on sustainable development together with balanced and harmonious relations among

Arquiteta e urbanista, mestre em Arquitetura e Urbanismo e doutoranda no Programa de Pós- Graduação em Arquitetura e Urbanismo da Universidade Federal de Santa Catarina (PósARQ/ UFSC), Quapá-SEL Floripa. Arquiteta do Instituto de Patrimônio Histórico e Artístico Nacional de Santa Catarina (IPHAN-SC). Campus Reitor João David Ferreira Lima, 88040-900, Caixa Postal 476, Trindade, Florianópolis, SC, Brasil.

vgdeluca@gmail.com

** $\quad$ Arquiteta e urbanista pela Universidade de Brasília (UnB). Mestre pela Université de Paris 12. Doutora pela Université Paris 1 Pantheon-Sorbonne. Professora no Programa de Pós-Graduação em Arquitetura e Urbanismo da Universidade Federal de Santa Catarina (PósARQ/UFSC), QuapáSEL Floripa. Campus Reitor João David Ferreira Lima, 88040-900, Caixa Postal 476, Trindade, Florianópolis, SC, Brasil. alinagsantiago@hotmail.com 
social, economic and environmental needs of each community in order to promote protection, management and development of landscapes. This way it is possible to protect the landscape by conservation and maintenance actions for significant or characteristic features of the landscape, justified by the patrimonial value resulting from its natural configuration or human intervention. As landscapes have always changed and will continue to change, either by natural processes or by human action, it is necessary to monitor the changes in order to enrich the diversity and the quality of each of them.

Keywords: Landscape character. Landscape character assessment. European Landscape Convention.

\section{INTRODUÇÃO}

A Convenção Europeia da Paisagem (CEP), aprovada em 2000, em Florença, compreende a relação entre aspectos naturais e culturais da paisagem com foco no desenvolvimento sustentável e na relação equilibrada e harmoniosa entre as necessidades sociais, econômicas e ambientais. Paisagem, segundo a Convenção (Council of Europe, 2000), é qualquer parte do território tal como a percebe a população, cujo caráter seja resultado da ação e da interação de fatores naturais e/ou humanos. Essa definição busca compreender a paisagem de maneira global - de modo a contribuir na qualidade do lugar no qual vive uma população -, reconhecendo-a como condição essencial para o bem-estar individual e social, para o desenvolvimento sustentável e como recurso que favorece a atividade econômica.

A intervenção sobre a paisagem é entendida como uma combinação entre proteção, gestão e ordenamento sobre um mesmo território: certas partes e elementos podem ser protegidos; outros aspectos, em particular os processos, gestionados - enquanto outros podem ser transformados voluntariamente. (COUNCIL OF EUROPE, 2000).

Para tanto, é necessário identificar as paisagens no conjunto do seu território. $\bigcirc$ inventário avalia a paisagem, identifica e considera os valores específicos que thes são atribuídos pelos intervenientes e pela população interessada. Assim, é possível estabelecer instrumentos que visem à proteção, gestão e/ou ao ordenamento da paisagem. Ao incidir sobre áreas naturais, rurais, urbanas, periurbanas, áreas terrestres, águas interiores e marítimas, a CEP categoriza as paisagens em três tipos: 1) paisagens de considerável importância; 2) paisagens ordinárias; 3) paisagens degradadas.

Segundo Ribeiro (2007, p. 54), poderiam ser definidas quais paisagens necessitam de proteção - de acordo com sua importância, atribuída em função de diferentes valores - e quais paisagens necessitam de políticas de remodelação e transformação.

Este artigo aborda o conceito de Caráter da Paisagem presente na definição de paisagem da CEP e apresenta um aporte teórico bem como das etapas de aplicação do estudo da paisagem no Reino Unido, nos Catálogos da Paisagem da Catalunha e nas Estratégias da Paisagem de Andaluzia, ambos no âmbito espanhol.

\section{O CARÁTER DA PAISAGEM}

Em 2002, a Coyntryside Agency e a Scottish Natural Heritage publicaram o Landscape Character Assessment: Guidance for England and Scotland (Avaliação do caráter da 
paisagem: guia para Inglaterra e Escócia; tradução das autoras) de autoria de Carys Swanwick. Trata-se de um manual que visa à sistematização dos procedimentos necessários à avaliação do caráter da paisagem enquanto ferramenta que pode ser utilizada no planejamento e no desenvolvimento sustentável da paisagem, apresentando a avaliação do caráter da mesma como um processo que auxilia na identificação das características culturais e naturais presentes na localidade.

Swanwick (2002) define paisagem como a relação entre as pessoas, o lugar e o resultado da maneira como diferentes componentes naturais (geologia, solo, clima, fauna e flora) e culturais (uso do solo histórico e atual, assentamentos e intervenções humanas) interagem e são percebidos. Atualmente, tanto a dimensão objetiva ou morfológica, em suas formas físicas e materiais, quanto a dimensão subjetiva ou simbólica da paisagem subsidiam as discussões acerca da configuração e análise das paisagens. A relação entre esses componentes é apresentada a seguir:

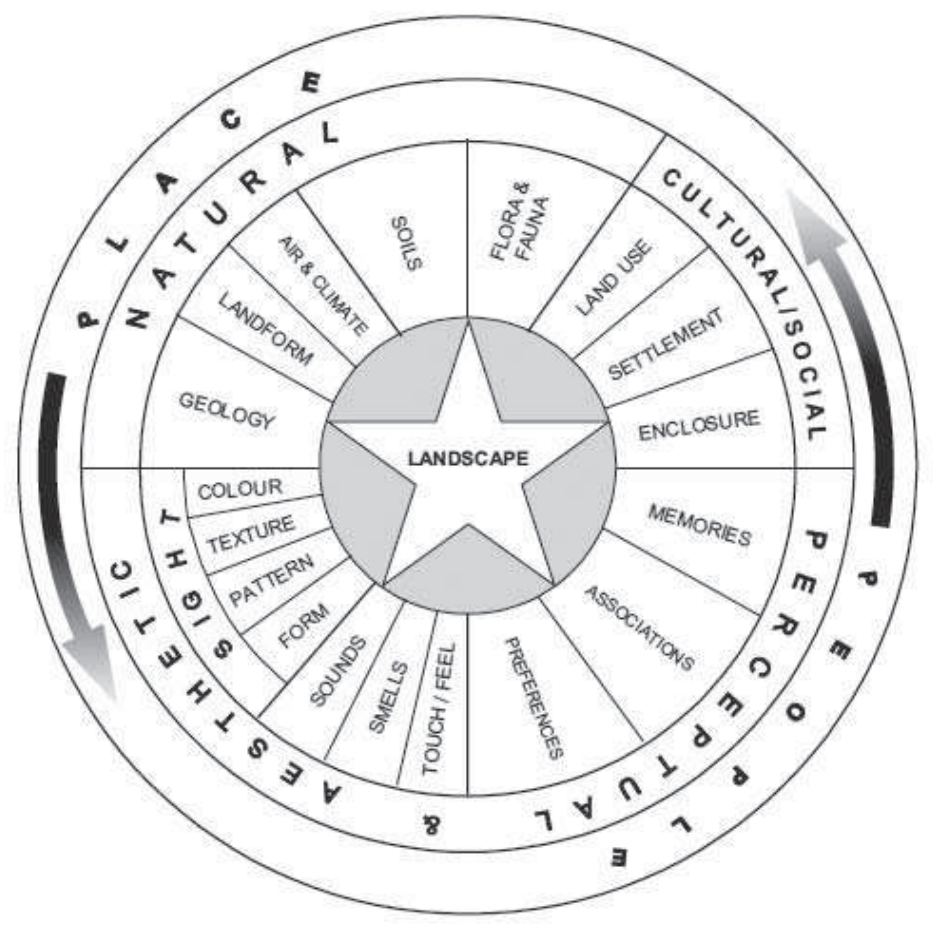

Figura 1 Diagrama da relação entre componentes da paisagem. Fonte: Swanwick (2002, p. 2).

O manual de Carys Swanwick apresenta o conceito de "caráter da paisagem" entendido como conjunto ou combinação particular, reconhecível e consistente de elementos, que torna uma paisagem diferente da outra e dá a cada uma delas um particular senso de lugar. Não se trata de quantificar o caráter das paisagens identificadas, mas, sim, de identificar quais fatores entre as combinações particulares de relevo, solo, vegetação, usos do solo, padrões de assentamento e parcelamento do solo contribuem para diferenciar as paisagens. (SWANWICK, 2002, p. 3-8). 
O caráter aparece na definição de paisagem da CEP e abarca importante conteúdo patrimonial, uma vez que o caráter de cada paisagem é resultado da ação de fatores naturais, humanos e de suas inter-relações: "Paisagem é qualquer parte do território tal como a percebe a população, cujo caráter seja resultado da ação e da interação de fatores naturais e/ou humanos." (COUNCIL OF EUROPE, 2000). Os aspectos patrimoniais atribuídos à paisagem pela CEP podem ser encontrados ao longo de todo o seu texto, apontando que sua proteção designa as ações de conservação ou manutenção dos traços significativos ou característicos de uma paisagem, justificadas pelo seu valor patrimonial, resultante de configuração natural e ou de intervenção humana. A CEP não reconhece a distinção entre os termos "paisagem natural" e "paisagem cultural" - pois natureza e cultura são aspectos indissociáveis -, utilizando apenas o termo "paisagem". Em sua configuração formal, a paisagem representa o elo entre sociedade, natureza e paisagens anteriores, a marca (ou sinal) que imprime caráter a cada território, o palimpsesto paisagístico. Nesse sentido, corrobora Mata:

É, não obstante, o Convênio Europeu da Paisagem que assume plenamente o sentido territorial da questão paisagística, quer dizer, a ideia inovadora desde o ponto de vista jurídico e político, de que cada território se manifesta na excepcionalidade de sua paisagem, independente da qualidade e de seu apreço. (MATA, 2010, p. 45).

Segundo o Landscape Character Assessment, a classificação da paisagem ocorre de dois modos, concentrando-se na identificação das características que tornam uma área diferente ou distinta de outra e classificando as paisagens em tipos e áreas de caráter, conforme o quadro 1.

Quadro 1 Distinção entre Tipo e Área de Caráter da Paisagem

\begin{tabular}{c|l}
\hline \multicolumn{1}{c|}{ Classificação } & \multicolumn{1}{c}{ Conceituação } \\
\hline $\begin{array}{l}\text { Tipo de caráter da paisagem } \\
\text { (caráter tipo) }\end{array}$ & $\begin{array}{l}\text { Tipo de paisagem de caráter relativamente homogêneo, genéricos, e pode } \\
\text { ocorrer em diferentes regiões, compartilhando combinações similares } \\
\text { de geologia, topografia, padrão de drenagem, vegetação, uso do solo } \\
\text { histórico e padrão de assentamento. }\end{array}$ \\
\hline Área de caráter da paisagem & $\begin{array}{l}\text { São únicas e referem-se a áreas geográficas onde ocorrem tipos específicos } \\
\text { de paisagem. }\end{array}$ \\
\hline
\end{tabular}

Fonte: Autoras. A partir de Swanwick (2002, p. 9).

Para Swanwick (2002), Zotano e Chueca (2010), o tipo de caráter da paisagem ou caráter tipo designa padrões similares de geologia, relevo, solo, vegetação, uso do solo e ocupação em toda a área de ocorrência. Não significa que toda a área seja idêntica, mas que existe um padrão comum que pode ser distinguido em mapas e pesquisas de campo. Nas avaliações locais, a ênfase encontra-se na identificação em menor escala, na qual tipos de caráter mais refinados representam padrões mais locais de caráter e contribuem para um senso de lugar mais local. As áreas de caráter 
possuem características genéricas em relação a áreas do mesmo tipo, mas têm identidade própria. Na maior parte dos casos, haverá mais áreas de caráter do que tipos de caráter, e alguns tipos ocorrerão em mais de uma área. As áreas de caráter são individuais, nas quais o caráter tipo ocorre mais detalhadamente, tratando-se de âmbito geográfico individual e geralmente conexo (não separado). Na escala do detalhe, cada área pode ser considerada composta por diversos tipos, cuja combinação específica do padrão dá lugar ao padrão distintivo que a individualiza. Em maior escala, compartilha seu domínio com outras áreas de mesmo tipo.

Para Zotano e Chueca (2010), qualquer classificação paisagística deve conter alguns requisitos: ser exaustiva (cumprir todo o espaço geográfico) e exclusiva (as unidades não podem se sobrepor); ser facilmente aplicável e reproduzida; incluir camadas de informação ligadas a três dimensões principais da paisagem: ecossistema, cênico-perceptiva, histórico-funcional; ser hierárquica, com unidades adaptadas às distintas escalas do território, e ser flexível, para admitir adaptações a novas necessidades conceituais ou aplicadas.

A avaliação' do caráter da paisagem adota uma abordagem holística, que considera a paisagem como um mosaico de diferentes tipos e áreas e engloba estágios de caracterização que se dividem em: identificação, mapeamento, classificação e descrição do caráter da paisagem. A tomada de decisão ${ }^{2}$ baseia-se no processo de caracterização da paisagem e informa o alcance das diferentes decisões relativas aos tipos de aplicação, superando, assim, as questões meramente estéticas e ecológicas da paisagem. Em relação ao enfoque metodológico, Swanwick (2002) aponta que a avaliação do caráter da paisagem apresenta quatro princípios: 1) ênfase no caráter da paisagem; 2) distinção clara entre processo de caracterização e tomada de decisão; 3) utilização de abordagens objetiva e subjetiva durante o processo; 4) aplicação em diferentes escalas.

\section{O CASO ESPANHOL}

No âmbito espanhol, os Catálogos da Paisagem aparecem como instrumentos para a introdução dos objetivos paisagísticos no planejamento territorial da Catalunha, estando definidos no Art. 10, $\S 1^{\circ}$ da Lei $8 / 2005^{3}$ como documentos de caráter descritivo e prospectivo que determinam a tipologia das paisagens da Catalunha, identificam seus valores, seu estado de conservação e propõem os objetivos de qualidade que devem cumprir:

Por uma questão semântica, utiliza-se "avaliação" no sentido de apreço e estima por algo (segundo o termo inglês evaluation), e não no sentido de valoração (segundo o termo inglês assessment), que dá título ao manual.

2 Do inglês, making judgements.

3 Llei 8/2005, de 8 de juny, de protecció, gestió i ordenació del paisatge. Catalunya, 2005. Diari Oficial de la Generalitat de Catalunya. Disponível em: <http://www.catpaisatge.net/fitxers/llei_paisatge.pdf> . Acesso em: 29 jun. 2012. 
Os Catálogos da Paisagem são as ferramentas que nos permitem conhecer como é a nossa paisagem e que valores têm, que fatores explicam que tenhamos um determinado tipo de paisagem e não outro, como a paisagem evolui em função de suas dinâmicas econômicas, sociais e ambientais, definem que tipo de paisagem queremos e como podemos consegui-la. (NOGUÉ; SALA, 2006, p. 10).

O Observatório da Paisagem é o órgão do Departamento de Política Territorial e Obras Públicas do Governo da Catalunha responsável por elaborar os Catálogos da Paisagem das sete regiões em que se organiza a estrutura política administrativa da Catalunha. A elaboração dos catálogos coincidiu com os trabalhos de redação ou revisão dos Planos Territoriais Parciais (Planos Diretores Parciais) realizados pelo Departamento. O Observatório desenvolveu o Prototipus de Catàleg de Paisatge 4 , que fornece orientações de maneira semelhante a um guia e estabelece as bases metodológicas e os critérios comuns para a elaboração dos sete catálogos de forma coerente e coordenada.

Conforme Nogué e Sala, não existe um método reconhecido universalmente para estudar, identificar e avaliar as paisagens e suas diversidades - ainda que na Europa exista uma importante base de conhecimento a respeito. Os autores ressaltam a experiência acumulada de países europeus, como Bélgica, Reino Unido (principalmente a Countryside Agency), França, Eslovênia e Espanha, em seus respectivos atlas paisagísticos, que buscam identificar e avaliar as paisagens em sua totalidade. São experiências de grande interesse, cujas principais diferenças em relação ao catálogo de paisagem da Catalunha se encontram no objetivo final e na sua integração no processo de apropriação dos planos territoriais parciais - uma das suas principais funções. (NOGUÉ; SALA, 2006).

Os catálogos partem de uma visão integrada da paisagem e consideram seus componentes naturais e culturais conjuntamente, nunca separados. Os autores destacam que o enfoque metodológico é qualitativo - em função da existência de dificuldades metodológicas e diferenças perceptivas a respeito da paisagem que dificultam a definição de um método quantitativo de valoração da qualidade da paisagem que seja válido e aceito por todos. Por essa razão, os catálogos da paisagem evitam a hierarquização de níveis de qualidade da paisagem e a quantificação de seus valores, uma tarefa muito complexa - para não dizer impossível - uma vez que a maioria dos valores responde a percepções ou sensações subjetivas e incomensuráveis da população.

Também baseada nos postulados da CEP, a metodologia dos Catálogos da Paisagem, segundo Nogué e Sala (2006), é clara e de fácil compreensão, demonstrando os passos a serem seguidos, a cartografia a ser gerada e os resultados a serem alcançados. A elaboração dos catálogos divide-se em cinco etapas: 1) identificação e caracterização da paisagem; 2) avaliação da paisagem; 3) definição de objetivos de qualidade paisagística; 4) estabelecimento de medidas e propostas de atuação; 5) estabelecimento dos indicadores de seguimento.

\footnotetext{
Protótipo de Catálogo da Paisagem (tradução das autoras).
} 
O principal objetivo dos catálogos encontra-se na fase de caracterização, cujo processo engloba identificação, mapeamento e descrição das áreas que apresentam certa coesão interna e de caráter próprio. Como primeira etapa do processo de caracterização, a identificação busca definir o caráter da paisagem e determinar os elementos naturais, culturais (materiais e imateriais) e visuais que diferenciam as paisagens. Permite, portanto, mapear as porções do território que possuem caráter próprio e inclui as seguintes etapas: delimitação de unidades de paisagem (hierarquizada em níveis de análise: unidades de paisagem e unidades de atenção especial); estudo da sequência evolutiva da paisagem; identificação dos valores da paisagem; identificação das dinâmicas atuais da paisagem; estudo da possível evolução da paisagem e descrição dos resultados obtidos para cada unidade de paisagem.

Assim como o Landscape Character Assessment, Nogué e Sala (2006) trabalham com tipos distintos de classificação de paisagem. Nos catálogos, a distinção se dá entre Unidades de Paisagem (UP) e unidades de atenção especial, embora ambas sejam conceitualmente semelhantes ao apresentado no manual do Reino Unido, como demonstram o quadro 2 e a figura 3 .

Quadro 2 Distinção entre Unidade de Paisagem e Unidade de Atenção Especial

\begin{tabular}{l|l}
\hline $\begin{array}{l}\text { Unidade de } \\
\text { paisagem (UP) }\end{array}$ & $\begin{array}{l}\text { Parte do território caracterizada por uma combinação específica de } \\
\text { componentes paisagísticos - de natureza ambiental, cultural e estética - e } \\
\text { por dinâmicas claramente reconhecíveis, que configuram uma idiossincrasia } \\
\text { diferenciada do restante do território. As UPs baseiam-se, principalmente, } \\
\text { nos elementos que estruturam o território (montanhas, rios, rede viária) e sua } \\
\text { organização (áreas agrícolas, florestas ou áreas urbanas) e na dinâmica que } \\
\text { contribuiu - e contribui - para moldar a imagem atual da tradição cultural } \\
\text { particular e da história, que são difíceis de identificar com a sobreposição do } \\
\text { simples mapeamento. O caráter das UPs depende, portanto, da combinação } \\
\text { de formas de relevo, cobertura do solo, organização do espaço, dimensão } \\
\text { histórica, percepção, alteraçães imediatas ou relações entre população e } \\
\text { paisagem (proximidade, laços emocionais, sentimento de pertençimento). }\end{array}$ \\
\hline $\begin{array}{l}\text { Unidades de } \\
\text { atenção especial }\end{array}$ & $\begin{array}{l}\text { Setores da paisagem com características muito singulares, porém de } \\
\text { pequena extensão territorial. São porções do território que apresentam } \\
\text { determinada heterogeneidade, complexidade ou singularidade do ponto } \\
\text { de vista paisagístico (por exemplo, zonas periurbanas em transformação } \\
\text { ou outros âmbitos com intensa e rápida transformação de seus usos) e que, } \\
\text { portanto, necessitam de diretrizes e critérios específicos para proteção, } \\
\text { gestão e ordenamento. }\end{array}$ \\
\hline
\end{tabular}

Fonte: Autoras. A partir de Nogué; Sala (2006, p. 30, 33).

A segunda etapa é a avaliação da paisagem, na qual são analisadas ameaças e oportunidades da mesma. Consideram-se quatro aspectos, analisados anteriormente: organização da paisagem; valoração da paisagem; dinâmicas da paisagem; estudo de possível evolução. Essa análise é extremamente útil para as fases seguintes, dedicadas ao planejamento da paisagem, à definição dos objetivos de qualidades da paisagem e a medidas e ações para alcançá-los. 
A terceira etapa - objetivos de qualidade paisagística -, assim como estabelece a CEP, corresponde à realização, por parte das autoridades públicas, das aspirações da comunidade no que diz respeito às características da paisagem e de seu entorno depois de conhecer o seu estado, os valores e riscos, tanto no âmbito territorial como para cada unidade de paisagem. $O$ estabelecimento de medidas e proposta de atuação corresponde à quarta etapa e determina, para cada UP ou unidade de atenção especial, diretrizes de paisagem que seriam integrantes dos planos territoriais parciais, ações e critérios específicos que devem empreender as administrações para alcançar os objetivos de qualidades da etapa anterior. Por fim, a quinta etapa corresponde ao estabelecimento de indicadores de seguimento - que define uma grade de indicadores de paisagem compreensível pela população, por políticos e gestores públicos, formulada a partir dos objetivos de qualidade paisagística, com o objetivo de monitorar o estado da paisagem da Catalunha e sua evolução num marco de desenvolvimento sustentável.

Ainda em relação ao estudo da paisagem, o Conselho da Europa (Council of Europe) lançou, em 2008, a Recomendación CM/Rec (2008)3 del Comité de Ministros a los estados miembros sobre las orientaciones para la aplicación del Convenio Europeo del Paisaje ${ }^{5}$, que compreende um conjunto de orientações teóricas, metodológicas e práticas para a aplicação da CEP. Os princípios gerais do documento apontam os artigos fundamentais da CEP, os quais buscam: considerar o território em sua totalidade; reconhecer o papel fundamental do conhecimento; promover a sensibilização; formular estratégias para a paisagem; integrar a paisagem nas políticas territoriais e setoriais; colocar em prática a participação pública; respeitar os objetivos de qualidade paisagística e desenvolver a assistência mútua e a troca de informações. (COUNCIL OF EUROPE, 2008, p. 4-6).

Segundo a Recomendação, a identificação, caracterização e qualificação das paisagens constituem a fase preliminar de qualquer política de paisagem. Essa etapa implica em uma análise da paisagem, nos planos morfológico, histórico, cultural e natural de suas inter-relações, e da análise de suas transformações. A percepção da paisagem deve, também, ser analisada desde o ponto de vista de seu desenvolvimento histórico até o seu significado recente. Outra etapa fundamental no processo que conduz à ação paisagística é a formulação dos objetivos de qualidade paisagística e o alcance desses objetivos mediante ações de proteção, gestão e ordenamento da paisagem no tempo - medidas e ações excepcionais e medidas e ações ordinárias. (COUNCIL OF EUROPE, 2008, p. 12).

O termo identificação é considerado em sentido amplo e está constituído por uma fase de compreensão e análise das características específicas (caracterização) e de uma fase de individualização dos problemas de qualidade (qualificação) conforme a complexidade das situações e os objetivos. Fica garantida, ainda, a formulação dos objetivos de qualidade paisagística - uma vez que certos elementos naturais e his-

Recomendação CM/Rec (2008)3 do Comitê de Ministros dos Estados Membros sobre as orientações para aplicação do Convênio Europeu da Paisagem (tradução das autoras). 
tóricos podem ser objetos de atenção particular para preservar seu papel específico, seu significado histórico particular, suas potencialidades ambientais. Essa etapa está fundamentada no conhecimento das características e qualidades específicas dos lugares, dinâmicas e percepção da população e pautada na geração de conhecimento, consulta à população, formulação de políticas, estratégias de ação e seguimento.

Ainda no âmbito espanhol, a Junta de Andalucía, no volume Estrategia da Paisaje de Andalucía $^{6}$, estabelece que a etapa de identificação consiste em designar e delimitar determinada paisagem a partir de uma série de recursos gerais que justificam sua diferenciação. Em último caso, a identificação de determinada paisagem é uma operação interpretativa pela qual se alcança elevado grau de abstração e síntese da realidade paisagística. A caracterização consiste na descrição dos recursos da paisagem atual e na explicação das causas dessa configuração, requerendo um ponto de vista holístico. Requer, também, aproximações mais específicas, centradas em questões concretas, principalmente nos fundamentos naturais e no processo histórico que têm levado à situação atual e às dinâmicas existentes. A qualificação implica um tipo de interpretação diferente: trata-se, sobretudo, de ler a paisagem como cenário portador de significados que são transmitidos culturalmente, de forma recorrente, e que por isso merecem ser preservados e adequadamente geridos. Esses valores ou significados procedem de diversas vias de transmissão: das próprias interações entre sociedade e meio e, também, da percepção social, presente nos discursos locais ou na tradição interpretativa e criativa de uma paisagem, que se manifesta em obras literárias, pictóricas ou cinematográficas. (JUNTA DE ANDALUCÍA, 2012, p. 84).

\section{CONSIDERAÇÕES FINAIS}

Os casos apresentados, tanto o do Reino Unido quanto o da Espanha, embora distintos nas etapas de estudos da paisagem, buscam cumprir os postulados da CEP7. Entre os casos apresentados, cabe destacar o do Observatório da Paisagem, que propõe paisagismo e planejamentos que priorizem o processo da participação popular consensual e intensivo.

Conforme Ribeiro (2007), as ideias da CEP estão intimamente ligadas ao desenvolvimento sustentável e buscam garantir o usufruto das paisagens pelas populações atuais e futuras. A Convenção reconhece que, na procura por um justo equilíbrio entre proteção, gestão e ordenação, é necessário levar em conta o fato de que não se procura preservar ou congelar as paisagens em um estado dado na sua longa evolução. As paisagens sempre mudaram e continuarão a mudar - tanto sob o efeito dos processos

Estratégia da Paisagem da Andaluzia. (tradução das autoras).

Artigo $4^{\circ}$ - Repartição de competências: Cada uma das Partes aplica a presente Convenção, em especial os Artigos $5^{\circ}$ e $6^{\circ}$, de acordo com a sua própria repartição de competências em conformidade com os seus princípios constitucionais e organização administrativa, respeitando o princípio da subsidiariedade, e tendo em consideração a Carta Europeia da Autonomia Local. Sem derrogar as disposições da presente Convenção, cada uma das Partes deve harmonizar a implementação da presente Convenção de acordo com as suas próprias políticas. (COUNCIL OF EUROPE, 2000). 
naturais, como da ação humana. Assim, considera-se que as paisagens evolvem no tempo sob o efeito das forças naturais e da ação dos seres humanos, sublinhando a ideia de que a paisagem forma um todo, no qual elementos naturais e culturais são considerados simultaneamente.

A avaliação do caráter da paisagem, por sua vez, reúne informações relativas ao ambiente físico, natural e histórico e permite abordagens mais integradas para auxiliar no planejamento e na gestão das paisagens. Desse modo, o planejamento e a gestão podem ser realizados para salvaguardar a peculiaridade e o caráter local - melhorados e aprimorados por meio do processo de desenvolvimento -, auxiliar em processos que busquem identificar quais características ambientais e culturais estão presentes em uma localidade, monitorar as alterações no ambiente e entender a sensibilidade de um local para o desenvolvimento.

\section{REFERÊNCIAS BIBLIOGRÁFICAS}

CATALUNYA. Llei 8/2005, de 8 de juny, de protecció, gestió i ordenació del paisatge. Diari Oficial de la Generalitat de Catalunya, 2005. Disponível em: < http://www.catpaisatge.net/fitxers/llei_paisatge.pdf>. Acesso em: 29 jun. 2012

COUNCIL OF EUROPE. Recomendación CM/Rec (2008)3 del Comité de Ministros a los estados miembros sobre las orientaciones para la aplicación del Convenio Europeo del Paisaje (versão em castelhano). Disponível em: <http://www.jcyl.es/web/jcyl/MedioAmbiente/es/Plantilla 100/1213710556304/_/__. Acesso em: 24 out. 2013.

COUNCIL OF EUROPE. 2000, Florença. EUROPEAN LANDSCAPE CONVENTION, Florença, 2000. Disponível em: <http://conventions.coe.int/Treaty/en/Treaties/Html/176.htm >. Acesso em: 14 mar. 2015.

JUNTA DE ANDALUCÍA. Estrategia de paisaje de Andalucía. Sevilla, 2012. Disponível em: <http://www. juntadeandalucia.es/medioambiente/portal_web/web/temas_ambientales/evaluacion_integracion_planificacion/ planificacion_ambiental/estrategias/estrategia_paisaje/Estrategia_de_Paisaje_de_Andālucia_2012.pdf $>$. Acesso em: 5 nov. 2013

MATA, Rafael Olmo. La dimensión patrimonial del paisaje. In: MADERUELO, Javier (Org.). Paisaje y patrimonio. Madri: Abada Editores, 2010, p. 31-73.

NOGUÉ, Joan; SALA, Pere. Prototipus de catáleg de paisatge: bases conceptuals, metodològiques i procedimentals per elaborar els catàlegs de paisatge de Catalunya. Olot i Barcelona. Catalunya: Observatori del Paisatge, 2006. Disponível em: <http://catpaisatge.net/fitxers/Prototipus2006.pdf>. Acesso em: 21 set. 2011.

RIBEIRO, Rafael Winter. Paisagem cultural e patrimônio. Rio de Janeiro: IPHAN/COPEDOC, 2007.152 p.

SWANWICK, Carys. Landscape Character Assessment: guidance for England and Scotland. Scottish Natural Heritage \& The Countryside Agency, 2002. Disponível em: <http://www.naturalengland.org.uk/ourwork/landscape/ englands/character/assessment/>. Acesso em: 17 jul. 2011.

ZOTANO, José Gómez; CHUECA, Pascual Riesco (Cord.). Marco conceptual y metodológico para los paisajes españoles: aplicación a tres escalas espaciales. Sevilla: Consejeria de Obras Públicas y Viviendas, Centro de estúdios Paisaje y Territorio, 2010. 467p. Disponível em: <http://www.paisajeyterritorio.es/index.php?option=com docman\&task=cat_view\&gid=42\&ltemid=95\&lang=en $>$. Acesso em: 10 ago 2013. 